\title{
The ROI-C zero-profile anchored spacer for anterior cervical discectomy and fusion: biomechanical profile and clinical outcomes
}

This article was published in the following Dove Press journal:

Medical Devices: Evidence and Research

18 April 2017

Number of times this article has been viewed

\section{Michael N Bucci' \\ Dennis $\mathrm{Oh}^{2}$ \\ R Scott Cowan ${ }^{3}$ \\ Reginald J Davis ${ }^{4}$ \\ Robert J Jackson ${ }^{5}$ \\ Dwight S Tyndall ${ }^{6}$ \\ Daniel Nehls ${ }^{7}$}

'Piedmont Spine and Neurosurgical Group, PA, Greenville, SC, USA;

${ }^{2}$ Baystate Medical Center, Springfield, MA, USA; ${ }^{3}$ New England Orthopedic Surgeons, Inc., Springfield, MA, USA; ${ }^{4}$ Greater Baltimore Medical Center, Baltimore, MD, USA; ${ }^{5}$ Orange County Neurosurgical Associates, Laguna Hills, CA, USA; ${ }^{6}$ Orthopedic Specialists of Northwest Indiana, Munster, IN, USA; ${ }^{7}$ Franciscan Neurosurgery Associates at St. Joseph Medical Center, Tacoma, WA, USA
Correspondence: Michael N Bucci Piedmont Spine and Neurosurgical Group, PA, 3 St. Francis Drive, Suite 490, Greenville, SC 2960I, USA

Tel +l 8642204263

Fax +l 8642205836

Email mb@piedneuro.com
Introduction: Anterior cervical discectomy and fusion (ACDF) has been the gold standard for treating cervical degenerative disc disease (cDDD). The use of anterior plates in ACDF poses an increased risk of complications such as screw or plate dislodgement, soft tissue injury, esophagus perforation, and dysphagia. The ROI-CTM implant system consists of a zero-profile interbody fusion cage with self-locking plates designed for stand-alone fusion without external plates or screws.

Objective: The purpose of this report is to describe the ROI-CTM implant system with VerteBRIDGETM anchor plates, including indications for use, surgical technique, preclinical testing, and clinical study results. The objectives of the clinical study were to assess fusion status, incidence of dysphagia and other device-related complications, and patient reported outcomes. Methods: This was a retrospective, multicenter cohort study of 110 patients who underwent ACDF with ROI-C at seven study centers. Patient charts and radiographs were reviewed for any complications or device malfunction. The final follow-up was conducted prospectively and included collection of neck disability index, and visual analog scale (VAS) neck and arm pain scores.

Results: The mean operation time was 73 minutes, and mean blood loss was $25 \mathrm{~mL}$ (range 0-75 mL). Mean follow-up was 20.7 months (range 9.5-42.2). Dysphagia was reported in two patients (1.8\%), and $99.1 \%$ of patients achieved fusion. One patient had radiographically confirmed pseudarthrosis at 12 months that was asymptomatic and did not require surgery. One patient had subsequent surgery owing to adjacent level degeneration. The mean neck disability index, VAS neck pain, and VAS right and left arm pain scores at final follow-up were 19, 26.5, 12.5 , and 15.3 , respectively.

Conclusion: The ROI-C interbody cage with VerteBRIDGE anchor plates achieved a high rate of fusion, with a low incidence of dysphagia. These patients had similar or better outcomes compared to ACDF with anterior plating reported in peer-reviewed literature.

Keywords: ROI-C, zero-profile spacer, ACDF, stand-alone cage, cervical disc degeneration

\section{Introduction}

Degenerative conditions of the cervical spine (eg, degenerative disc disease or cervical spondylotic myelopathy) are characterized by the degeneration of the intervertebral discs of the cervical spine. Cervical disc degeneration is a common cause of neck pain. A damaged vertebral disc due to degenerative disc disease can cause discogenic pain; however, not all degenerated discs cause pain. In addition to having the low-grade pain of a stiff or inflexible neck, many patients with cervical disc degeneration have numbness, tingling, or even weakness in the neck, arms, or shoulders as a result of nerves in the cervical area becoming irritated or pinched. Aging, genetics, metabolic 
disorders, and mechanical stress are known risk factors for cDDD. ${ }^{1}$ The progression of cDDD can lead to the collapse of the intervertebral space, disc herniation, spinal stenosis, and radicular arm pain with or without neurologic deficit. If conservative therapy fails, patients frequently undergo anterior cervical discectomy and fusion (ACDF). Since the initial description of ACDF by Smith and Robinson as well as by Cloward, ${ }^{1,2}$ many technical modifications have been reported.

Currently, surgeons may use autologous bone graft, allograft, synthetic material, and/or interbody cages as interposition grafts. The use of anterior iliac bone graft for anterior interbody fusion has been the gold standard for decades. Although highly successful fusion is achieved by autologous iliac bone graft, the use of this graft has greatly diminished owing to donor-site morbidity. ${ }^{3-7}$

Interposition grafts are often combined with anterior locking plates to increase the immediate postoperative stability after bone grafting between vertebral bodies. Anterior plates enhance rigidity of fixation and decrease risk of nonunion, which may lead to kyphosis and pseudarthrosis, particularly in multilevel cases. ${ }^{8-12}$ Moreover, anterior plating may also reduce the risk of graft extrusion. ${ }^{13}$ However, implantation of a plate in the anterior cervical spine poses an increased risk of hardware-related complications such as screw or plate dislodgement, soft tissue injury, esophagus perforation, nerve palsy, and dysphagia, and may contribute to adjacent level degeneration and osteophyte formation. ${ }^{14-19}$

To prevent these complications, cages have been studied and applied in humans as potential bone substitutes for autograft in interbody fusion. The ROI-C ${ }^{\text {TM }}$ implant system (ROI-C, Zimmer Biomet, Austin, TX, USA) is composed of the ROI-C zero-profile interbody fusion cage with VerteBRIDGETM self-locking plates designed for stand-alone fusion. First clinical use of the ROI-C occurred in 2008, and in February 2009, the US Food and Drug Administration approved the ROI-C system for single-level treatment of degenerative cervical spine conditions. The purpose of the clinical study was to assess the occurrence of fusion, dysphagia, and other short-term complications, and the postoperative effectiveness in patients who underwent ACDF with the ROI-C system.

\section{ROI-C ${ }^{\text {TM }}$ with VerteBRIDGE ${ }^{\text {TM }}$}

The ROI-C implant system consists of "D"-shaped blocks in a variety of footprints and heights (Figure 1). The ROI-C implant system is comprised of a radiolucent Polyetheretherketone (PEEK) Optima ${ }^{\circledR}$ LT1 cage with tantalum alloy radiologic position markers. PEEK is a nonabsorbable biopolymer that has been used in a variety of industries, including medical devices. The PEEK cages are biocompatible, radiolucent, and have modulus of elasticity similar to bone. The ROI-C titanium-coated implant offers a porous plasma titanium coating made of unalloyed nonferromagnetic titanium (Ti), sprayed onto the superior and inferior surfaces of the implant.

The curved shape of the ROI-C anatomic implants allows for optimum surface area contact with vertebrae that embody a curved surface morphology. Both the ROI-C and ROI-C titanium-coated implant systems include a lordotic shape as well, which allows for optimum surface area contact with vertebrae that embody a flat surface morphology. To promote faster rates of fusion, the ROI-C cage features an enclosed chamber that may be filled with autologous or allogenic bone graft. To prevent device migration and provide increased joint stability, both the superior and the inferior surfaces of the implants have a pattern of teeth.

The ROI-C implant system is intended for insertion using an anterior approach. In order to provide the stability needed for successful fusion, the cage is implanted with two VerteBRIDGE anchor plates. The VerteBRIDGE plates are manufactured from surgical titanium (Ti6Al4V), and are used to affix the ROI-C implant to the superior and inferior vertebral bones of the index level. The VerteBRIDGE anchor plate technology allows the ROI-C implant to be used as a
A

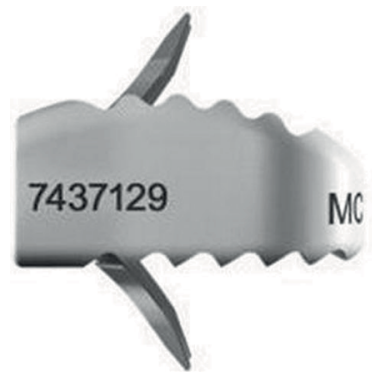

B

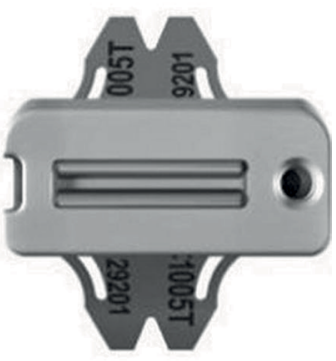

C

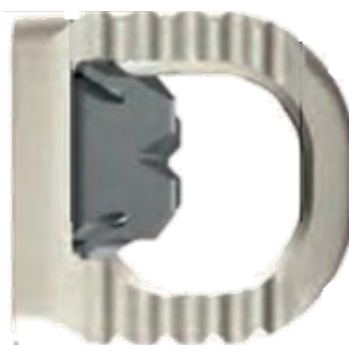

Figure I The ROI-C cervical cage with VerteBRIDGE plating technology. Notes: (A) Lateral view; (B) Anterior view; (C) Superior view. 
stand-alone construct, although supplemental fixation may be used as patient needs dictate.

\section{Indications for use}

The ROI-C implant system is indicated for use in skeletally mature patients with cervical degenerative disc disease (cDDD) with accompanying radiculopathy and/or myelopathy at a single disc level from $\mathrm{C} 2$ to $\mathrm{T} 1$. These patients should have 6 weeks of nonoperative treatment unless they have severe or progressive neurologic dysfunction. The ROI-C implants are intended for use with autogenous or allogenic bone graft composed of cancellous and/or corticocancellous bone graft.

The ROI-C implant system is implanted via an open, anterior approach. Supplemental internal fixation with two VerteBRIDGE anchor plates is required to use this system properly. The ROI-C implant system has been designed to be compatible with optional supplemental fixation specifically for the system using the VerteBRIDGE anchor plates to affix the ROI-C cage to the underlying vertebral bone, and to specifically allow for the option of a stand-alone construct. Additional or other supplemental fixation may be used, as patient needs dictate.

\section{Surgical technique}

The ROI-C is designed for implant as an intervertebral spacer via the anterior approach. The patient is positioned supine, and radiographic imaging is obtained in the anterior-posterior (AP) and lateral planes to identify the level of diseased $\operatorname{disc}(\mathrm{s})$, sizing and placement of the implant, and plate insertion. After successful general anesthesia, the basic techniques for exposure, discectomy, and decompression are performed using a standard right- or left-sided approach. When indicated, the posterior longitudinal ligament is resected to allow for excision of extruded disc material and/or to determine the appropriate intervertebral disc height. The endplates are abraded before fusion by removing the cartilaginous tissue from the endplates using surgeon preferred tools such as rongeurs, curettes, or shaving spatulas. Only the cartilaginous portion of the vertebral endplate is removed, and the bony endplate is preserved as much as possible to prevent cage subsidence.

After the midline is determined, the cage trial is used. The ROI-C trials have the same dimensions as the implants and provide optimal endplate coverage, height restoration, and stability. The trial is placed in front of the space to visually determine width, and the selected trial is inserted into the space. Under lateral radiographic imaging the following are confirmed:
- Implant depth and height

- Endplate coverage (AP)

- Conformity with the superior dome for the anatomic design

- Restoration of the lordotic curve for the lordotic design.

The distraction is released in order to assess the height that will best restore the anatomic shape of the operated space, as well as the best stability to the implant. The trial should not protrude past the edge of the vertebrae.

The trial is then removed, and the appropriate-sized final cage endplates are inserted to an adequate depth under lateral fluoroscopic guidance. The central space of the ROI-C may be filled with autologous bone to facilitate bony integration. The cage is then inserted into the disc space using an impactor. The implant is inserted by gently tapping the end of the implant holder as necessary. If the implant position is too anterior, the AP positioning can be adjusted by dialing the adjustable stop from 0 to $5 \mathrm{~mm}$. For each millimeter the depth stop advances, the implant moves $1 \mathrm{~mm}$ posterior.

Under radiographic imaging, insertion of the implant is completed, and a final assessment of implant depth and endplate coverage is performed. A tantalum marker is located $1 \mathrm{~mm}$ from the posterior implant edge for positioning reference. The surgeon should verify that the marker is at least 1 or $2 \mathrm{~mm}$ anterior to the canal to avoid compression of the dura mater. Following this, AP and lateral fluoroscopy is performed to confirm the appropriate positioning and size of the device.

After implantation of the cage, the two cervical anchoring clips are placed into the lower and upper vertebra through the anterior part of the cage to ensure primary stabilization by the self-locking function of the anchoring clips. The VerteBRIDGE plates are inserted one after the other, as the plate paths cross in the plate housing portion of the implant holder (ie, the plate inserted into the cranial slot will be anchored into the caudal vertebral body, and the plate inserted into the caudal slot will be anchored in the cranial vertebral body). The second plate can be inserted only after the first plate is locked. Upon radiographic confirmation of plate location, the implant holder is removed, and the surgical incision is irrigated and closed in the standard manner.

Standard surgeon practice should be followed for postoperative care after implantation, including normal precautions for cervical fusion. As many of these procedures are done in an outpatient setting, most patients are ambulatory on the day of surgery. 


\section{Preclinical evidence}

\section{Biomechanical evaluation of the ROI-C}

The ROI-C system was subjected to preclinical biomechanical testing to assess stability and pullout force. The aim of this study was to biomechanically evaluate the ROI-C construct compared to conventional bone grafts with anterior plating and to stand-alone PEEK cages with integrated screws.

Cadaveric motion segments from two cervical spines ( $\mathrm{C} 2-$ C3, C4-C5, and C6-C7) were mounted in epoxy and tested using a hydraulically actuated spinal loading system (MTS 810, MTS Systems, Eden Prairie, MN, USA). The flexibility protocol using application of pure moments was chosen to provide a direct comparison to the intact specimens, as well as to published data. Pure moments of $2.5 \mathrm{Nm}$ in flexion-extension, bilateral lateral bending, and axial torsion were applied with a $20 \mathrm{~N}$ machine-applied axial preload to maintain compression of the segment. Pullout testing was used to compare resistance to expulsion. Force was applied at $10 \mathrm{~mm} / \mathrm{min}$ under a $50 \mathrm{~N}$ axial preload to measure peak extraction loads. The vertebrae were allowed to rotate during pullout testing.
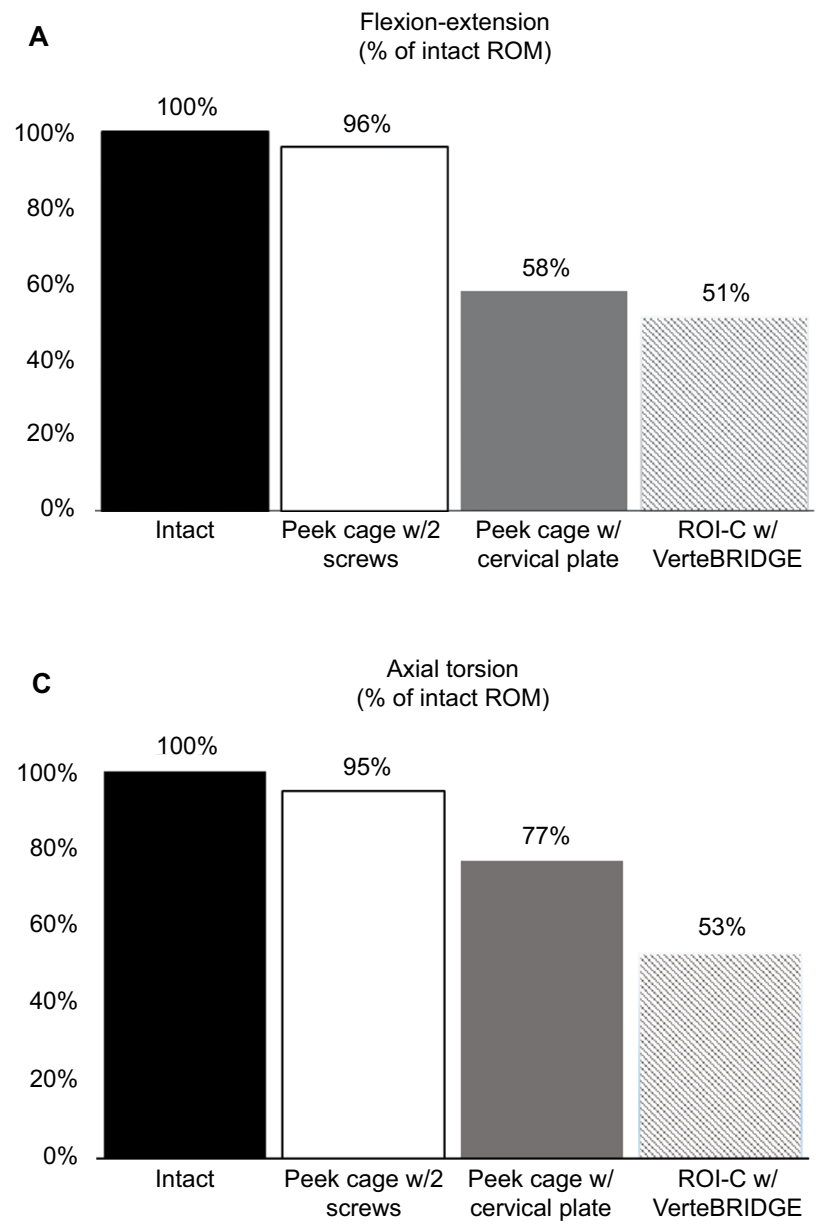

The intact construct averaged $12.9 \pm 3.6^{\circ}$ in flexionextension, $9.7 \pm 2.6^{\circ}$ in lateral bending, and $10.3 \pm 1.3^{\circ}$ in axial torsion. Range of motion (ROM) of the ROI-C with VerteBRIDGE plates was $39 \%-53 \%$ relative to the intact construct, with mean flexion-extension of $6.6 \pm 3.3^{\circ}$, lateral bending of $3.8 \pm 2.4^{\circ}$, and axial torsion of $5.5 \pm 2.5^{\circ}$. In each test direction, the range of motion of ROI-C was significantly reduced $(p \leq 0.01)$ compared to the intact specimen. ROI-C also had less range of motion (\% of Intact ROM) in all directions compared to a stand-alone PEEK cage with two screws, as well as to a traditional PEEK cage with cervical plate construct (Figure 2). Average pullout loads for ROI-C were greater than reported pullout loads for a conventional cervical plate ( $232.7 \mathrm{~N}$ vs $202 \mathrm{~N}$, respectively), which are well above the expected physiologic loads. ${ }^{20}$ Pullout failure of the ROI-C only occurred due to plowing of the device through the bone and opening (lordosing) of the segment.

In flexion-extension, lateral bending, and axial torsion, the ROI-C with VerteBRIDGE anchoring plates showed lower ROM than published data ${ }^{21}$ of a similar stand-alone PEEK

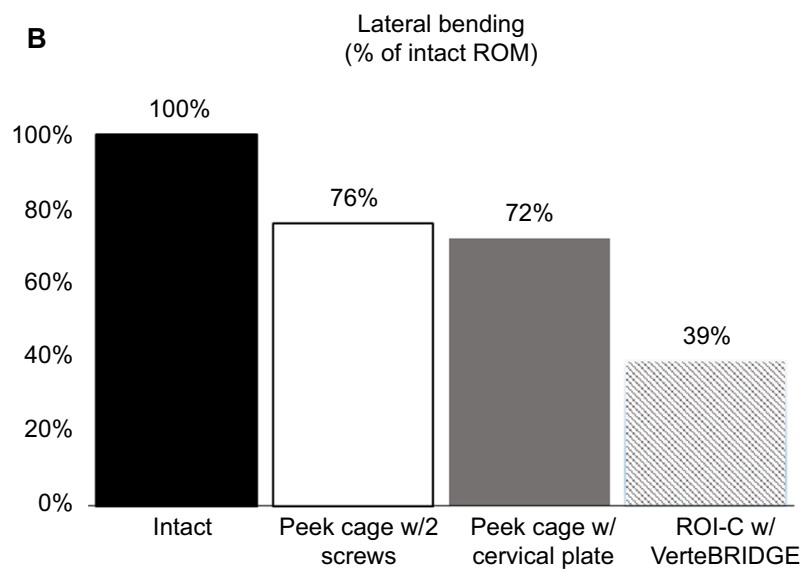

Figure 2 Range of motion of ROI-C with VerteBRIDGE anchor plates, Polyetheretherketone (PEEK) cage with anterior plating, and PEEK cage with screws. Notes: Range of motion is expressed as a percentage of the Intact specimen ROM. Data for PEEK Cage obtained from Freeman et al. ${ }^{21}$ Abbreviations: ROM, range of motion; w/, with; w/2, with 2 
cage with two integrated screws and a conventional construct comprised of a PEEK cage and metal cervical plate. The pullout resistance of the ROI-C with VerteBRIDGE plating is comparable to published data ${ }^{22}$ of a bone graft with cervical plate and screws. When additional resistance to expulsion vs a cage alone is desired, the ROI-C with VerteBRIDGE plating was shown to be a viable option.

\section{Clinical evidence ROI-C retrospective study}

\section{Methods}

This was a retrospective, multicenter study of patients who underwent single-level ACDF with the stand-alone configuration of the ROI-C cage with VerteBRIDGE anchor plates and autograft bone (Figure 3). Surgical data and patient demographic information were collected from 110 patients at seven study centers in the US (Registration number NCT02104167; ClinicalTrials.gov). All patients signed a written informed consent to take part in the study. The Western Institutional Review Board (IRB) approved the study protocol for five centers, and approval was granted at two centers by local hospital IRBs (Baystate Medical Center, Springfield, MA, USA; St. Joseph Medical Center, Tacoma, WA, USA). Inclusion criteria included a diagnosis of DDD at one level between $\mathrm{C} 2$ and $\mathrm{T} 1$ with radiculopathy and/or myelopathy confirmed by radiographic imaging and corresponding pain and/or neurologic deficit. Implants occurred between January 2011 and November 2013. All patients were consented prior to data collection. Data were collected retrospectively from the preoperative and operative periods, and at 2 and 6 months. The final follow-up visit was conducted prospectively between December 2013 and January 2015. Fusion status was determined using AP, lateral, and flexion/extension radiographs at each time point, and was defined by the presence of bridging bone with less than $2^{\circ}$ segmental motion in flexion/extension
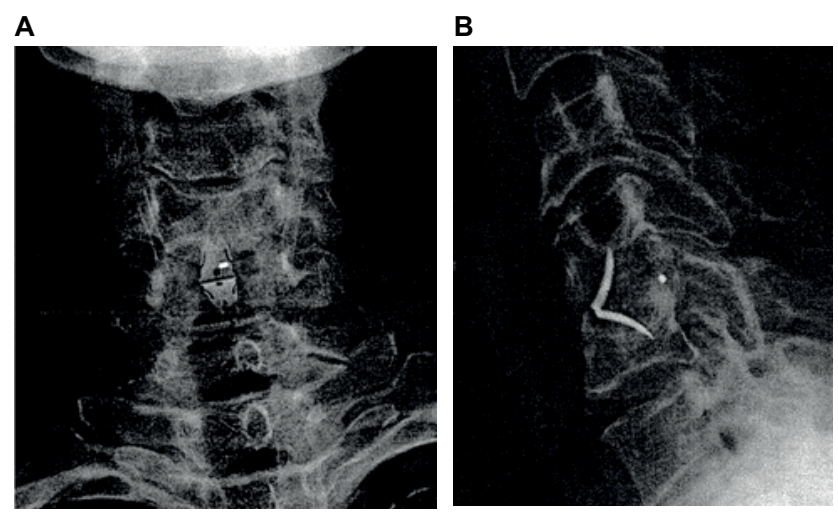

Figure 3 Postoperative radiographs of the ROI-C with VerteBRIDGE anchor plates at the C4-C5 level.

Notes: (A) anterior-posterior view; (B) lateral view. and less than $3 \mathrm{~mm}$ of AP translation. Device integrity was assessed radiographically for subsidence, pseudarthrosis, and device-related complications. Clinical examination at the final follow-up included measurement of neck disability index (NDI), and measurement of neck and radicular arm pain using a visual analog scale (VAS) of 0-100, with 0 representing no pain and 100 representing severe pain. Adverse events and dysphagia were also collected. Study outcomes were compared to results from recent publications of ACDF. Literature controls were obtained from peer-reviewed publications of US Food and Drug Administration randomized studies reporting the 2-year outcomes of single-level ACDF with plate and screws.

\section{Results}

The study cohort included 64 females and 46 males. The mean age was $51.9 \pm 10.2$ years (Table 1). Twenty-eight patients $(25.5 \%)$ had undergone previous cervical spine surgery. All patients presented with radiculopathy and/or myelopathy with pain and paresthesia. All procedures were single-level ACDF with the ROI-C. Operated levels included C3-C4 through C7-T1. Autograft was added to the cage in each case, and no supplemental fixation was used. The mean

Table I Preoperative and operative details

\begin{tabular}{|c|c|}
\hline \multicolumn{2}{|l|}{ Preoperative characteristics } \\
\hline Patients, $\mathrm{n}$ & 110 \\
\hline Age, mean \pm standard deviation (range) & $51.9 \pm 10.2(24-75)$ \\
\hline \multicolumn{2}{|l|}{ Gender, n (\%) } \\
\hline Female & $64(58.2 \%)$ \\
\hline Male & $46(41.8 \%)$ \\
\hline $\mathrm{BMI}\left(\mathrm{kg} / \mathrm{m}^{2}\right)$, mean \pm standard deviation & $29.8 \pm 5.7$ \\
\hline Obese $\left(B M I \geq 30 \mathrm{~kg} / \mathrm{m}^{2}\right), \mathrm{n}(\%)$ & $52(47.3 \%)$ \\
\hline Previous cervical spine surgery, n (\%) & $28(25.5 \%)$ \\
\hline Smoking, n (\%) & $16(14.5 \%)$ \\
\hline \multicolumn{2}{|l|}{ Diagnosis, n (\%) } \\
\hline Radiculopathy & $57(52.3 \%)$ \\
\hline Myelopathy & $14(12.8 \%)$ \\
\hline Radiculopathy + Myelopathy & $38(34.9 \%)$ \\
\hline Not reported & 1 \\
\hline \multicolumn{2}{|l|}{ Operative characteristics } \\
\hline \multicolumn{2}{|l|}{ Operated Levels, n (\%) } \\
\hline $\mathrm{C} 3-\mathrm{C} 4$ & 13 ( I I.8\%) \\
\hline C4-C5 & $16(14.5 \%)$ \\
\hline $\mathrm{C} 5-\mathrm{C} 6$ & $40(36.4 \%)$ \\
\hline $\mathrm{C} 6-\mathrm{C} 7$ & $38(34.5 \%)$ \\
\hline C7-TI & $3(2.7 \%)$ \\
\hline $\begin{array}{l}\text { Operative time (minutes), mean } \pm \text { standard } \\
\text { deviation (range) }\end{array}$ & $73 \pm 22(30-161)$ \\
\hline Blood loss (mL), mean (range) & $25(0-75)$ \\
\hline $\begin{array}{l}\text { Hospital stay (days), mean } \pm \text { standard } \\
\text { deviation (range) }\end{array}$ & $0.7 \pm 0.5(0-2)$ \\
\hline Follow-up time (months), mean (range) & $20.7(9.5-42.2)$ \\
\hline
\end{tabular}


Table 2 Outcomes at final follow-up in the ROI-C study

\begin{tabular}{lll}
\hline Outcome & $\begin{array}{l}\text { ROI-C with } \\
\text { VerteBRIDGE } \\
\text { (mean 20.8 months) }\end{array}$ & $\begin{array}{l}\text { ACDF w/plating } \\
\text { (I 2-24 months) }\end{array}$ \\
\hline NDI & 19.0 & $|0-40 .|^{34-38,49-5 \mid}$ \\
VAS neck & 26.5 & $|6-3|^{34-38,49-51}$ \\
VAS arm & & $8-28^{34-38,49-5 \mid}$ \\
Left arm & 15.3 & \\
Right arm & 12.5 & $2.9 \%-9.8 \%{ }^{34-38,49-52}$ \\
Secondary surgery & $0.9 \%$ &
\end{tabular}

Abbreviations: ACDF, anterior cervical discectomy and fusion; NDI, neck disability index; VAS, visual analog scale.

operation time was 73 minutes. Mean estimated blood loss was $25 \mathrm{~mL}$ (range $0-75 \mathrm{~mL}$ ). Patients left the hospital after an average stay of 0.7 days (range $0-2$ days).

The mean follow-up time was $20.7 \pm 8.8$ months. The mean NDI, VAS neck pain, VAS right arm pain, and VAS left arm pain scores at the final follow-up visit were 19, 26.5, 12.5, and 15.3, respectively (Table 2). Rates of dysphagia were $8.2 \%, 2.3 \%$, and $1.8 \%$ at 2 months, 6 months, and 12 months, respectively (Table 3 ). Fusion was achieved in $29.2 \%$ of patients at 2 months, $85.7 \%$ at 6 months, and $99.1 \%$ of patients at the final follow-up visit.

There was one instance of pseudarthrosis $(0.9 \%)$ and one secondary surgery $(0.9 \%)$. One patient had radiographically confirmed pseudarthrosis at 12 months. This patient was asymptomatic (NDI score $=4$; neck and arm pain scores $=0$ ) and did not undergo surgical treatment. The second patient, who initially underwent a $\mathrm{C} 3-\mathrm{C} 4$ procedure with ROI-C, presented with a diagnosis of cervical stenosis with myelopathy at multiple adjacent levels (C4-C6). Although the ROI-C had successfully fused, the patient had subsequent $\mathrm{C} 3-\mathrm{C} 6$ fusion 8 months after the initial procedure.

\section{Discussion}

In the current study, we demonstrate that the zero-profile ROI-C cage allows for similar or better clinical and radiographic outcomes compared with ACDF with anterior plating. During the postoperative follow-up period, no internal fixation loosening, detachment, fractures, instability, or subsidence occurred in our study. Subsidence of an interbody cage can lead to a variety of complications, including loss of foraminal and disc height, segmental spinal instability, and loss of lordosis. ${ }^{23}$ Preserving the cortical endplates is a critical factor in preventing interbody cage subsidence, and it has been proven that endplate preparation decreases the strength and stiffness of the vertebral bodies. ${ }^{24,25}$ The surgical technique of the ROI-C implant system requires minimal preparation of the endplates, and the clinical evidence suggests that ROI-C and other interbody fusion cages should have low subsidence rates because of this. ${ }^{24}$

Compared to ACDF with plate and screws, implant of the ROI-C leaves less hardware in the patient. Moreover, while use of the ROI-C cage does not always mean a smaller skin incision compared to ACDF using a plate; it does involve less dissection and a smaller exposure in the prevertebral space. The associated benefit is less trauma to the surrounding soft tissues. It also holds distinct advantages when doing a C7-T1 fusion, where one would not need to expose further caudally than the disc space itself. Implant of the ROI-C is particularly valuable in cases where there is an existing plate at an adjacent level. Such cases would require a much bigger exposure extending to the other end of the plate to remove it, in order to place a new plate across the new target level. With the ROI-C, there is no need to remove an existing adjacent plate, in fact no need to expose it at all, as it can just be left alone. In the occasional situation where the anchor encounters an existing screw in the shared vertebral body, the screw can just be removed and not the entire plate, which requires minimal extension of exposure.

Because nonunion has been linked to poor outcomes, ${ }^{10}$ the primary goal of ACDF is to achieve solid bony fusion, which prevents delayed kyphotic deformity with concomitant foraminal stenosis that may cause root compression and neck pain. ${ }^{26,27}$ We found that the ROI-C was associated with a high rate of bony fusion (99.1\%). Grasso et $\mathrm{al}^{28}$ and Wang et $\mathrm{a}^{29}$ reported $100 \%$ fusion in ROI-C patients followed for 2 years, and Hoffstetter et $\mathrm{al}^{30}$ reported similar fusion rates for ROI-C (95.2\%) vs ACDF (96\%) after a mean follow-up of 13.9 months. Increased rates of fusion have been reported in $\mathrm{ACDF}$ with anterior plating compared with $\mathrm{ACDF}$ without

Table 3 Rates of dysphagia and fusion for ROI-C compared to literature

\begin{tabular}{lllll}
\hline Outcome & \multicolumn{2}{c}{ ROI-C with VerteBRIDGE } & \multicolumn{2}{c}{ ACDF w/plating (I 2-24 months) } \\
\cline { 2 - 4 } & $\mathbf{2}$ months & $\mathbf{6}$ months & Final follow-up & \\
\hline Dysphagia & $8.2 \%$ & $2.3 \%$ & $1.8 \%$ & $0.7 \%-17.1 \% \%^{35,37,40,49-51,53}$ \\
Fusion & $29.2 \%$ & $85.7 \%$ & $99.1 \%$ & $89 \%-100 \% 34-38$ \\
\hline
\end{tabular}

Notes: aMean follow-up of 20.8 months.

Abbreviations: ACDF, anterior cervical discectomy and fusion. 
plate. ${ }^{13,31-33}$ Fusion rates of ACDF with cervical plating have been estimated to be $97.1 \%$ for single-level procedures. ${ }^{33}$ Comparatively, randomized control clinical trials involving patients treated with ACDF with anterior plating and allograft bone had fusion rates of $89 \%$ to $96.6 \%$ at 24 months. ${ }^{34-38}$

The zero-profile ROI-C anchored cage combines interbody support and supplemental fixation into a single device. An integral part of the ROI-C system is the two VerteBRIDGE anchoring plates, which eliminate the basic disadvantage of stand-alone cages. These unique structures offer a fixation mechanism that is similar to the function of a plate and screws. We believe that the self-locking VerteBRIDGE plates ensure excellent primary stability of the implant and promote early fusion. Furthermore, the elastic modulus of the anchored cage is similar to that of bone, which theoretically helps to decrease stress shielding and increase bony fusion. The anatomical shape of the anchored cage (with its upper convex part in the frontal and sagittal planes) allows a wide grafting space and close contact between the endplate bone and the implant.

In our study, the ROI-C implant system with VerteBRIDGE anchoring plates demonstrated low rates of dysphagia at $6(2.3 \%)$ and 12 months (1.8\%), respectively. Other studies of ROI-C have reported similarly low rates of dysphagia $(0 \%-3.1 \%) .{ }^{28-30}$ In contrast, dysphagia rates as high as $35.1 \%$ have been reported after ACDF with anterior plating. ${ }^{39}$ Several studies suggest that the use of anterior locking plates is associated with a higher rate of postoperative dysphagia. ${ }^{13,40,41}$ Bazaz et $\mathrm{al}^{40}$ observed a lower rate of dysphagia (14.1\%) in patients without anterior plating compared with the case in patients $(21.1 \%)$ who received a construct including an anterior locking plate. Mobbs et $\mathrm{a}^{13}$ observed a similar trend, with a significantly higher rate of dysphagia in patients who received an anterior locking plate $(4.5 \%)$ compared with constructs without anterior plating $(0.8 \%)$.

Although the causes of dysphagia after ACDF procedures are not well understood, several physiologic mechanisms have been proposed. The occurrence of dysphagia and dysphonia has been linked to causes such as damage or compression of the soft tissues of the trachea or esophagus from the anterior plate ${ }^{41,42}$ or scar tissue from the incision..$^{43}$ Irritation or impingement can occur because the anterior cervical locking plate is placed directly posterior to the esophagus. ${ }^{13,40,41,44}$ The design and thickness of anterior locking plates also correlate with postoperative dysphagia ${ }^{41}$ Another possible mechanism for postoperative dysphagia after ACDF with anterior plating may be additional traction required to place an anterior locking plate. Increased pressure on the esophagus during implantation of an anterior plate has been suggested to contribute to dysphagia in patients who undergo ACDF with anterior plating. ${ }^{45} \mathrm{In}$ contrast, the ROI-C implant system stabilizes the joint without the need for anterior plating. This zero-profile design decreases the likelihood for dysphagia and dysphonia by avoiding compression of the soft tissues, and the use of the curved anchor plates instead of screws allows for a smaller surgical incision that does not extend beyond the size of the cage.

There is a growing consensus that ACDF alters the natural history of cervical spondylosis and hastens the development of degenerative changes at levels immediately above and below fused regions. In this retrospective study, one patient $(0.9 \%)$ had adjacent segment degeneration that required a subsequent fixation at an adjacent level. Hofstetter et $\mathrm{al}^{30}$ reported that two ROI-C patients (5.7\%) required repeat surgery for adjacent level disease. Schwab et a ${ }^{46}$ found that cervical fusion reduced the number of vertebrae with active function and caused biomechanical changes. To maintain the function of the entire cervical spine, the body increases the activity of the adjacent fused vertebral segments to compensate, causing adjacent segment degeneration. The presence of a plate and screws is also likely to accelerate degenerative changes in adjacent segments, ${ }^{47}$ and anterior interbody fusion can also contribute to adjacent segment degeneration, ${ }^{48}$ but the exact pathophysiologic mechanism of adjacent segment degeneration remains unknown.

\section{Conclusion}

The design of the ROI-C implant system utilizes the core principles of previous interbody cages to take advantage of the safety and successful clinical history of anterior interbody fusion devices, while addressing some of the drawbacks of previous interbody implants. The clinical results of the ROI-C implant system have demonstrated positive clinical outcomes with high fusion rates and low rates of subsidence, dysphagia, reoperation, and adjacent segment degeneration. The elegant design and ease of use of the ROI-C with VerteBRIDGE locking plates represent an improved surgical option for a stable anterior interbody fusion without the need for anterior plating or posterior fixation. Possible advantages of the ROI-C for spinal fusion surgery include a short operative time, less dissection and smaller exposure of the prevertebral space, and less implanted hardware, with the associated benefit of less trauma to the surrounding soft tissues.

\section{Acknowledgments}

The current affiliation of Dr Reginald J Davis is Tampa Laser Spine Institute, Tampa, FL 33607. Data analysis and 
preparation of the draft manuscript, tables, and figures were performed by W B Dolman (Zimmer Biomet).

\section{Disclosure}

This study was supported by LDR Spine USA, Inc. (now Zimmer Biomet). Each of the authors was an investigator in the ROI-C retrospective study and received research support during the study. MNB and RJJ have served as consultants for LDR and Zimmer Biomet. The authors report no other conflicts of interest in this work.

\section{References}

1. Cloward RB. The anterior approach for removal of ruptured cervical disks. J Neurosurg. 1958;15:602-617.

2. Smith GW, Robinson RA. The treatment of certain cervical-spine disorders by anterior removal of the intervertebral disc and interbody fusion. J Bone Joint Surg Am. 1958;40A:607-624.

3. Banwart JC, Asher MA, Hassanein RS. Iliac crest bone graft harvest donor site morbidity. A statistical evaluation. Spine (Phila Pa 1976). 1995;20:1055-1060.

4. Arrington ED, Smith WJ, Chambers HG, Bucknell AL, Davino NA. Complications of iliac crest bone graft harvesting. Clin Orthop. 1996;329:300-309.

5. Goulet JA, Senunas LE, DeSilva GL, Greenfield ML. Autogenous iliac crest bone graft: Complications and functional assessment. Clin Orthop. 1997;339:76-81.

6. Sawin PD, Traynelis VC, Menezes AH. A comparative analysis of fusion rates and donor-site morbidity for autogeneic rib and iliac crest bone grafts in posterior cervical fusions. J Neurosurg. 1998;88:255-265.

7. Silber JS, Anderson DG, Daffner SD, et al. Donor site morbidity after anterior iliac crest bone harvest for single-level anterior cervical discectomy and fusion. Spine (Phila Pa 1976). 2003;28(2):134-139.

8. Bohler J, Gaudernak T. Anterior plate stabilization for fracture-dislocations of the lower cervical spine. J Trauma. 1980;20:203-205.

9. Connolly PJ, Esses SI, Kostuik JP. Anterior cervical fusion: outcome analysis of patients fused with and without anterior cervical plates. J Spinal Disord Tech. 1996;9:202-206.

10. Kaiser MG, Haid RW Jr, Subach BR, Barnes B, Rodts GE Jr. Anterior cervical plating enhances arthrodesis after discectomy and fusion with cortical allograft. Neurosurgery. 2002;50:229-236.

11. Fujibayashi S, Neo M, Nakamura T. Stand-alone interbody cage versus anterior cervical plate for treatment of cervical disc herniation: sequential changes in cage subsidence. J Clin Neurosci. 2008; 15:1017-1022.

12. Song KJ, Taghavi CE, Lee KB, Song JH, Eun JP. The efficacy of plate construct augmentation versus cage alone in anterior cervical fusion. Spine (Phila Pa 1976). 2009;34:2886-2892.

13. Mobbs RJ, Rao P, Chandran NK. Anterior cervical discectomy and fusion: analysis of surgical outcome with and without plating. J Clin Neurosci. 2007;14:639-642.

14. Lowery GL, McDonough RF. The significance of hardware failure in anterior cervical plate fixation. Patients with 2- to 7-year follow-up. Spine (Phila Pa 1976). 1998;23(2):181-186.

15. Fujibayashi S, Shikata J, Kamiya N, Tanaka C. Missing anterior cervical plate and screws: a case report. Spine (Phila Pa 1976). 2000;25(17): 2258-2261.

16. Orlando ER, Caroli E, Ferrante L. Management of the cervical esophagus and hypofarinx perforations complicating anterior cervical spine surgery. Spine. 2003;28(15):E290-E295.

17. Jung A, Schramm J, Lehnerdt K, Herberhold C. Recurrent laryngeal nerve palsy during anterior cervical spine surgery: a prospective study. J Neurosurg Spine. 2005;2(2):123-127.

18. Fountas KN, Kapsalaki EZ, Nikolakakos LG, et al. Anterior cervical discectomy and fusion associated complications. Spine Phila Pa (1976). 2007;32(21):2310-2317.
19. Park J-B, Cho Y-S, Riew KD. Development of adjacent-level ossification in patients with an anterior cervical plate. J Bone Joint Surg. 2005;87-A(3):558-563.

20. Funk JR, Cormier JM, Bain CE, Guzman H, Bonugli E, Manoogian SJ. Head and neck loading in everyday and vigorous activities. Ann Biomed Eng. 2011;39(2);766-776.

21. Freeman AL, Beaubien BP, Castro CA, et al. Biomechanical evaluation of a new stand-alone cervical interbody device versus traditional fixation techniques. Poster 1711 presented at: 55th Annual Meeting of the Orthopaedic Research Society; February 22-25, 2009; Las Vegas, NV.

22. Ames CP, Crawford NR, Chamberlain RH, Deshmukh V, Sadikovic B, Sonntag VK. Biomechanical analysis of a resorbable anterior cervical graft containment plate. Spine. 2005;30:1031-1038.

23. Amelot A, Bouazza S, George B, Orabi M, Bresson D. Anterior extrusion of fusion cage in posttraumatic cervical disk disease. J Neurol Surg A Cent Eur Neurosurg. 2015;76(2):168-171.

24. Oxland TR, Grant JP, Dvorak MF, Fisher CG. Effects of endplate removal on the structural properties of the lower lumbar vertebral bodies. Spine. 2003;28(8):771-777.

25. Cheng C-C, Ordway NR, Zhang X, Lu YM, Fang H, Fayyazi AH. Loss of cervical endplate integrity following minimal surface preparation. Spine. 2007;32:1852-1855.

26. Murphy MA, Trimble MB, Piedmonte MR, Kalfas IH. Changes in the cervical foraminal area after anterior discectomy with and without a graft. Neurosurgery. 1994;34:93-96.

27. Thorell W, Cooper J, Hellbusch L, Leibrock L. The long-term clinical outcome of patients undergoing anterior cervical discectomy with and without intervertebral bone graft placement. Neurosurgery. 1998; 43:268-273.

28. Grasso G, Giambartino F, Tomasello G, Iacopino G. Anterior cervical discectomy and fusion with ROI-C PEEK cage: cervical alignment and patient outcomes. Eur Spine J. 2014;23(Suppl 6):S650-S657.

29. Wang Z, Jiang W, Li X, et al. The application of zero-profile anchored spacer in anterior cervical discectomy and fusion. Eur Spine J. 2015;24: 148-154.

30. Hofstetter CC, Kesavabhotla K, Boockvar JA. Zero-profile anchored spacer reduces rate of dysphagia compared to ACDF with anterior plating. J Spinal Disord Tech. 2015;28:E284-E290.

31. Caspar W, Geisler FH, Pitzen T, Johnson TA. Anterior cervical plate stabilization in one- and two-level degenerative disease: overtreatment or benefit? J Spinal Disord Tech. 1998;11:1-11.

32. Geisler FH, Caspar W, Pitzen T, Johnson TA. Reoperation in patients after anterior cervical plate stabilization in degenerative disease. Spine (Phila Pa 1976). 1998;23:911-920.

33. Fraser JF, Hartl R. Anterior approaches to fusion of the cervical spine: a metaanalysis of fusion rates. J Neurosurg Spine. 2007;6: 298-303.

34. Sasso RC, Smucker JD, Hacker RJ, Heller JG. Artificial disc versus fusion: a prospective, randomized study with 2-year follow-up on 99 patients. Spine. 2007;32:2933-2940.

35. Murrey D, Janssen M, Delamarter R, et al. Results of the prospective, randomized, controlled multicenter Food and Drug Administration investigational device exemption study of the ProDisc-C total disc replacement versus anterior discectomy and fusion for the treatment of 1-level symptomatic cervical disc disease. Spine J. 2009;9: 275-286.

36. Hisey MS, Bae HW, Davis R, et al. Multi-center, prospective, randomized, controlled investigational device exemption clinical trial comparing Mobi-C cervical artificial disc to anterior discectomy and fusion in the treatment of symptomatic degenerative disc disease in the cervical spine. Int J Spine Surg. 2014;8(1):7.

37. Vaccaro A, Beutler W, Peppelman W, et al. Clinical outcomes with selectively constrained Secure-C cervical disc arthroplasty: two-year results from a prospective, randomized, controlled, multicenter investigational device exemption study. Spine. 2013;38:2227-2239.

38. Phillips FM, Lee JYB, Geisler FH, et al. A prospective, randomized, controlled clinical investigation comparing PCM cervical disc arthroplasty with anterior cervical discectomy and fusion. Spine. 2013;38:E907-E918. 
39. Yue WM, Brodner W, Highland TR. Persistent swallowing and voice problems after anterior cervical discectomy and fusion with allograft and plating: a 5- to 11-year follow-up study. Eur Spine J. 2005;14:677-682.

40. Bazaz R, Lee M, Yoo J. Incidence of dysphagia after anterior cervical spine surgery: a prospective study. Spine. 2002;27(22):2453-2458.

41. Lee MJ, Bazaz R, Furey CG, Yoo J. Influence of anterior cervical plate design on dysphagia: a 2-year prospective longitudinal follow-up study. J Spinal Disord Tech. 2005;18:406-409.

42. Stein MI, Nayak AN, Gaskins RB 3rd, Cabezas AF, Santoni BG, Castellvi AE. Biomechanics of an integrated interbody device versus ACDF anterior locking plate in a single-level cervical spine fusion construct. Spine J. 2014;14(1):128-136.

43. Frempong-Boadu A, Houten JK, Osborn B, et al. Swallowing and speech dysfunction in patients undergoing anterior cervical discectomy and fusion: a prospective, objective preoperative and postoperative assessment. J Spinal Disord Tech. 2002;15(5):362-368.

44. Hodges SD, Humphreys SC, Eck JC, Covington LA, Van Horn ER, Peterson JE. A modified technique for anterior multilevel cervical fusion. J Orthop Sci. 2002;7:313-316.

45. Tortolani PJ, Cunningham BW, Vigna F, Hu N, Zorn CM, McAfee PC. A comparison of retraction pressure during anterior cervical plate surgery and cervical disc replacement: a cadaveric study. J Spinal Disord Tech. 2006;19:312-317.

46. Schwab JS, DiAngelo DJ, Foley KT. Motion compensation associated with single-level cervical fusion: where does the lost motion go? Spine Phila Pa (1976). 2006;31(21):2439-2448.
47. Kao FC, Niu CC, Chen LH, Lai PL, Chen WJ. Maintenance of interbody space in one- and two-level anterior cervical interbody fusion: comparison of the effectiveness of autograft, allograft, and cage. Clin Orthop Relat Res. 2005;430:108-116.

48. Maldonado CV, Paz RD, Martin CB. Adjacent-level degeneration after cervical disc arthroplasty versus fusion. Eur Spine J. 2011;20(3): 403-407.

49. Skeppholm M, Lindgren L, Henriques T, Vavruch L, Löfgren H, Olerud C. The Discover artificial disc replacement versus fusion in cervical radiculopathy - a randomized controlled outcome trial with 2-year follow-up. Spine J. 2015;15:1284-1294.

50. Gornet MF, Burkus K, Shaffrey ME, Argires PJ, Nian H, Harrell FE Jr. Cervical disc arthroplasty with PRESTIGE LP disc versus anterior cervical discectomy and fusion: a prospective, multicenter investigational device exemption study. J Neurosurg Spine. 2015;23(5):558-573.

51. Coric D, Nunley PD, Guyer RD, et al. Prospective, randomized, multicenter study of cervical arthroplasty: 269 patients from the Kineflex $\mid \mathrm{C}$ artificial disc investigational device exemption study with a minimum 2-year follow-up: clinical article. J Neurosurg Spine. 2011;15: 348-358.

52. Lubelski D, Healy AT, Silverstein MP, et al. Reoperation rates after anterior cervical discectomy and fusion versus posterior cervical foraminotomy: a propensity-matched analysis. Spine J. 2015;15:1277-1283.

53. McAfee P, Cappuccino A, Cunningham B, et al. Lower incidence of dysphagia with cervical arthroplasty compared with ACDF in a prospective randomized clinical trial. J Spinal Disord Tech . 2010;23:1-8.
Medical Devices: Evidence and Research

\section{Publish your work in this journal}

Medical Devices: Evidence and Research is an international, peerreviewed, open access journal that focuses on the evidence, technology, research, and expert opinion supporting the use and application of medical devices in the diagnosis, monitoring, treatment and management of clinical conditions and physiological processes. The identification of nove

\section{Dovepress}

devices and optimal use of existing devices which will lead to improved clinical outcomes and more effective patient management and safety is a key feature. The manuscript management system is completely online and includes a quick and fair peer-review system. Visit http://www. dovepress.com/testimonials.php to read real quotes from authors. 